\title{
Mob Analysis and Surveillance System (M.A.S.S.)
}

\author{
Mr. Ravindra Pardeshi, Mr. Manish Karandikar, Mr. Avinash Shilimkar \\ DCP, SB Nagpur Police, Maharashtra, India \\ President, Jigyasa Research and Development Center, Nagpur, India \\ PI, SB Nagpur Police Nagpur, Maharashtra, India
}

\begin{abstract}
Whenever law enforcement agency tries to gather information on mobs and public safety, it became increasingly clear that the primary factor in assuring a safe and comfortable environment for the large mob is the planning for their management. There is a considerable emphasis in this paper on Mob management planning and implementation because the police and other law enforcement agencies believe that it is the key to providing safe events in tense situations. Mob management must take into account all the elements of an event especially the type of events (circus, sporting, theatrical, concert, rally, parade, etc.), characteristics of the facility, size and demeanor of the mob, methods of entrance, methods of gathering, place and purpose of gathering, communications among various fractions of big mob, and queuing. As in all management, it must include planning, organizing, staffing, directing and evaluating. Particularly critical to mob management is defining the roles of parties involved in an event, the quality of the advance intelligence, and the effectiveness of the planning process. The main aim is to avoid disaster and, in case mob goes out of control, the next immediate aim is a minimum loss of life and property and rapid action and effective disaster management.
\end{abstract}

Keywords: Mob Management, drone, helmet, surveillance, disaster management, Crowd Management, Public Safety in India.

\section{Introduction}

Mob control is a public security practice where large mobs are managed to prevent the outbreak of mob crashes, affray, and fights involving notorious, drunk and disorderly people or riots. Mob clashes, in particular, can cause many hundreds of fatalities. Mob control and mob management techniques are often used at large, public gatherings like street fairs, concert, rally, parade and public demonstrations. At some events, security guards and police use metal detectors and sniffer dogs to prevent weapons and drugs being brought into a venue.

Materials such as mob control barriers, fences, and decals painted on the ground can be used to direct a mob. Keeping the mob comfortable and relaxed is also essential, so things like awnings, cooling fans, drinking water, and entertainment is sometimes used as well. Even after taking strong measures to maintain law and order and protect public life and property, we are still witnessing stampedes periodically. A lot of statistical data on stampedes and rioting during rallies and different agitations is available in digital and print format.

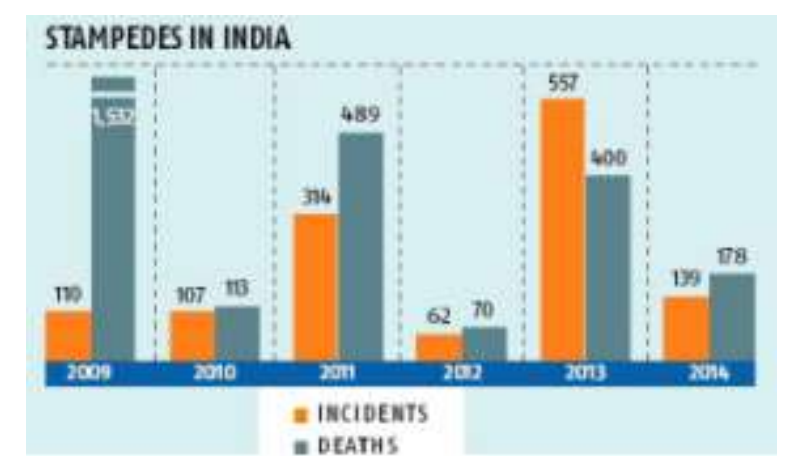

Source

http://www.business-standard.com/article/specials/story-in-numbers-stampedes-make-life-cheap-in-india116102400038_1.html

On October 15, a stampede during a religious procession on the Rajghat Bridge between Varanasi and Chandauli in Uttar Pradesh left 25 people dead, including 20 women. In July last year, about 27 people died in a stampede in Andhra Pradesh during the Godavari Pushkaralu, a festival where the river is worshiped and devotees take a dip in it.

The highest number of incidents occurred in 2009 (1,532), while the highest number of lives were lost in 2011 (489). The least number of deaths was in 2006 (18). 
In 2011, about 100 people each lost their lives in Andhra Pradesh, Tamil Nadu, and Kerala. The average number of deaths per year in the past seven years (2008-14) is almost three times the average number in the first seven years (2001-07).

All such data and previous experience of handling complicated task of Mob Management prompted Nagpur police to improve and experiment with new techniques to control all mob activities that too during asensitive period like winter session of Maharashtra Assembly. Hence, along with conventional methods of mob control and mob management, Nagpur Police with thetechnical team of Embedded Creations developed and successfully used the new MASS system that is Mob Analysis and Surveillance System. This was the first of its kind unique experiment and exercise carried out by ever developing and innovative team of police officers from Nagpur.

Maharashtra is the only state in India to have two assembly sessions at two different places. As per agreement during the formation of Maharashtra state, it was decided to take winter session of Maharashtra Assembly in second capital of Maharashtra (Nagpur).Since then the winter session at Nagpur is a big task from administrative and security aspect. Moving entire machinery and bandobast from Mumbai to Nagpur really takes huge planning and is a very critical task.

Security of all VIP and VVIP is the most important task. Considering global threat of terrorism to riots and stampedes and agitations of local people, police needs to keep strict vision on all activities. To keep full watch on all activities near sensitive areas like VidhanBhavan, SB branch of police department came up with the unique and novel method of Mob Analysis and Surveillance System of MASS.In this system drone cameras and helmet cameras were pressed into action and vital data was collected.

This data can be used to control and analyze mob characteristics and behaviors using the technique of image processing.

There are two important aspects of MASS system

1. Use of Drone camera for bird's eye view on all mob activity

2. Use of Helmet Cameras for behavioral characteristics of various groups in Mob.

Both the tools, that is, Drone and Helmet Cameras are the input devices and data acquisition tools. The data from helmet cameras is collected on acentral server using Wi-Fi network for live streaming or data is collected using file transfer technique at repeated interval of 3 to 5 minutes.

Once data is on theserver the MASS software takes over. The results of this software are yet to be tested on live streaming from theon-field activity. But we have completed our lab testing on recorded data.

\section{M.A.S.S. and Drone}

Drone is capable of providing many accurate details with 5 to 10 times better resolution than Google maps. We have obtained $3 \mathrm{~cm}$ per pixel accuracy. With this accuracy, we can find every small and large detail and keep a very close eye on all mob activity from a height of 100 to 200 meters.

The images provide following important data.

1. The restless small groups within huge gathering.

2. The flash points in mob behavior.

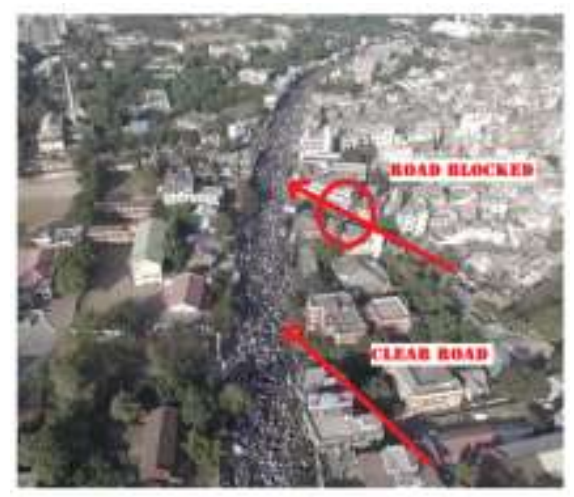

3. The congestion in nearby areas which may cause hurdles in disaster management and rapid action.

4. The shortest clear path that can be taken by police personnel and ambulance to reach the troubled area.

5. The nearest hospitals and other important places. 


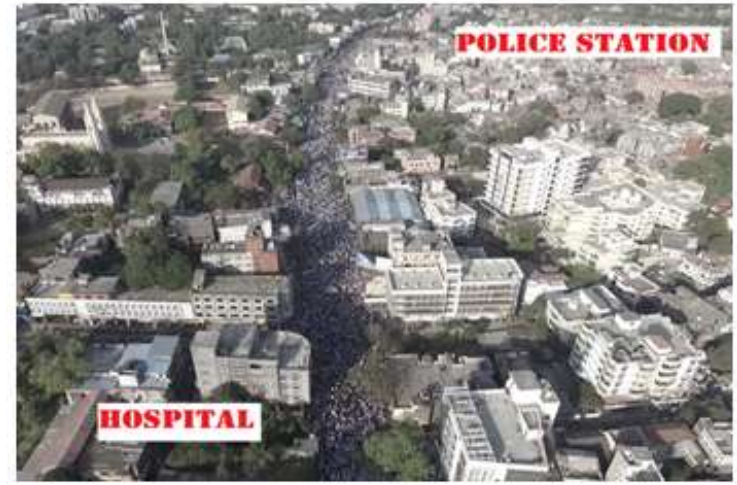

6. The safe exit points which can be used to disperse mob without causing stampede like situation.

\section{M.A.S.S. and Helmet Camera.}

1. The helmet cameras provide another smart dimension to the M.A.S.S. software. The helmet camera gathers close images of all activities in alarge gathering.

2. The helmet camera collects face and audio details which are not possible with CCTV installed on electric poles.

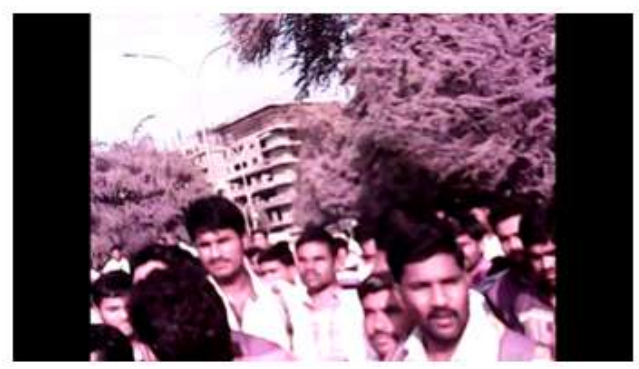

3. The face recognition side of M.A.S.S detects faces and tries to match them with police records.

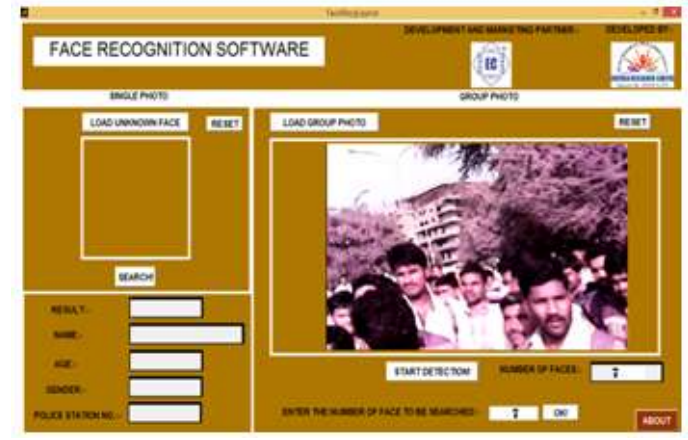

4. Any presence of history-sheeters or individuals with notorious police records can be identified. And special watch can be kept on the activities of these elements.

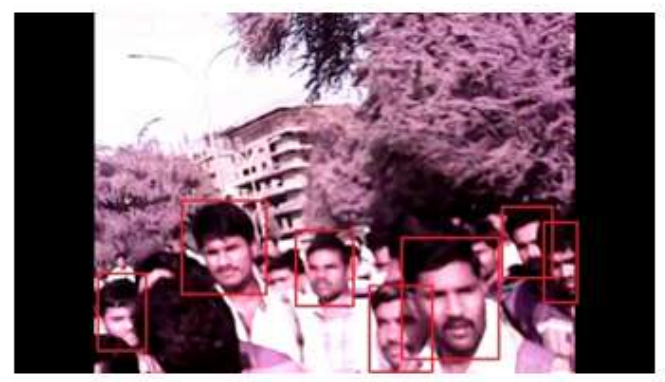

5. Repeated presence of any individual or a group of people in all rallies or gatherings can be identified.

6. Any provocative speeches or use of abusive language can be recorded as evidence in thecase of rioting. 


\section{Conclusion}

In this rapidly developing world, the importance of digital data and evidence collection is going to be the most important aspect for law enforcement agencies. The purpose of this paper is to motivate the research in this area of Mob Management and its implications on Law and Order issue. Police depart and some dedicated research institutions are working on these factors of national interest. But we are expecting more participation from intellectuals, industries, and universities. The more the research the better is technology and it leads to more sophisticated and efficient tools for law enforcement.

\section{References}

[1]. http://www.business-standard.com/article/specials/story-in-numbers-stampedes-make-life-cheap-in-india-116102400038_1.html

[2]. https://www.police.ucsb.edu/files/docs/Crowd-Management-Intervention-and-Control.pdf

[3]. http://ndma.gov.in/images/pdf/managingcrowdsguide.pdf

[4]. http://www.respect.org.in/img/topics/org-1476680801_org-

1436865040_Crowd\%20Management\%20\&\%20Public\%20Safety\%20in\%20India-\%20A\%20New\%20Policy\%20Intiative.pdf 